\title{
A Viewpoint of IT Big Data System to National Security by Coast Guard Government
}

\author{
Tsai-Fen Cheng ${ }^{1}$, CW Chen ${ }^{2}$ and CYJ Chen ${ }^{3 *}$ \\ ${ }^{1}$ National Kaohsiung University of Science and Technology, Taiwan \\ ${ }^{2}$ National Kaohsiung University of Science and Technology, Taiwan \\ ${ }^{3}$ University of Melbourne, Melbourne, Victoria, Australi ${ }^{a}$ \\ *Corresponding author: CYJ Chen, University of Melbourne, Melbourne, Victoria, Australia

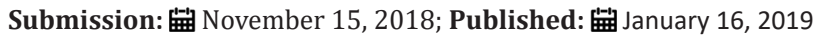

\begin{abstract}
The development of digital information technology drives the development of big data. The development of big data not only represents huge amounts of data, advanced information technology, and huge business opportunities, but also an effective way to solve problems, transform the world, and explore new ideas and scientific applications in the future. Therefore, this paper aims solving the current crime problem and provides the national security in order to keep society the transformation of the criminal environment, the reduction of criminal opportunities, the resolution of crime problems, and the prevention and treatment of future crimes.
\end{abstract}

Keywords: Big data; Information technology; Database system; Criminal searching

\section{Introduction}

Big data is usually time-sensitive and must be used immediately after streaming to the computing server for immediate high value. As the speed of data generation continues to rise, more data will be recorded, transmitted and stored instantly through the network or sensors. High-efficiency and automated computing systems, such as Streams Computing, must be applied for analysis. In order to create higher profits, the private sector will strive to shorten the collection and analysis processing time [1,2]. Due to the process of collecting, storing and analysing data, there may be "inaccuracy" in big data analysis due to misunderstanding or disoperation of the miscellaneous people, or the inaccuracy of the calculation system. As a result, the quality of the collected data is mixed, and the presentation of data can be inconsistencies, incompleteness, ambiguity, delays, deceptions, model approximations, and so on.

\section{Methodology-The Data Base System}

Recently, the development of big data has not only entered commercial trade, but also affected many industries. It has also been regarded as a key technology to enhance industrial competition and government effectiveness. The international community is actively investing in the research and application of big data. However, in order to pursue profit, the business operation is different from the government's people-oriented, emphasizing low-cost and efficiency. As Harvard Business Review puts it, big data is essentially a "management change," and it needs to improve the overall management model and technology integration to make a difference. The application field spans the financial management, retail channels, disease prevention, health care, energy conservation, transportation, humanities education and other technologies, and can even expand the social aspects of disaster relief and humanitarian assistance.

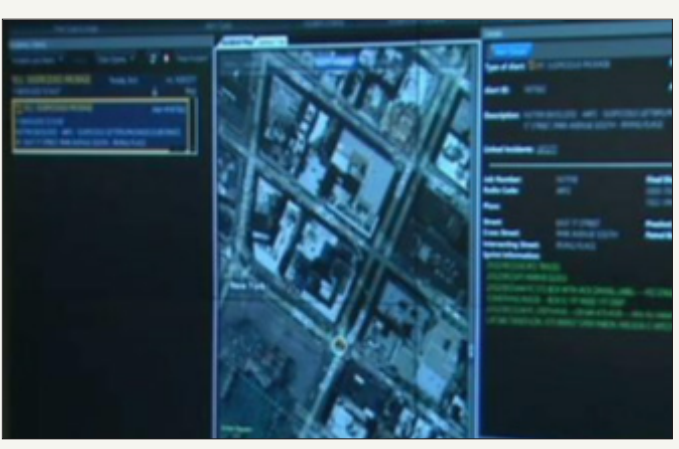

Figure 1: Domain awareness system DAS.

Dights are reserved by CYJ Chen 
Global Internet search leader Google's Google MAP navigation system, using the GPS positioning system of each Android operating system smart phone, to repay their position and speed at any time (the smart phone sensor can monitor the user's speed With the direction of movement "acceleration, direction", after the big data transmission to the cloud, the system can analyze the road conditions, Google can collect the most complete real-time traffic information [3,4]. Domain Awareness System DAS Figure 1 is based on the Lower Manhattan Security Initiative, a block south of Wall Street in New York City, the system collects and analyzes images of cameras, license plates, sensors, and law enforcement databases. News. Through the system, New York City police officers and investigators can quickly access suspected arrest records, suspected incidental phone calls, and related criminal incidents in specific areas. Crime maps can also be drawn within the system to show the pattern of crimes. And track the location of the suspect's vehicle now and in the past.
The Criminal Police Department's intelligent "Criminal Knowledge Base" shown in Figure 2 integrates the criminal records, transfer, overnight, etc. of the Ministry of the Interior, the Ministry of the Interior, the Immigration Department, the Department of Housing, the Ministry of Justice, the courts of the courts, and the supervision and supervision departments of the Ministry of Communications. Criminal investigation data such as investigation, judgment and execution, and collection of information on household registration, national identity card photos, medical records of former prisoners, prisoner information, gang rogue information, pawn, entry and exit, car registration, and evidence verification [5-7]. After the criminal case, you can use the advanced techniques of data mining, full-text search and cross-departmental information integration to analyze the criminal cases in the past and quickly bring relevant cases and suspicious persons into violations. The photo and its accomplice structure were provided to the investigating police officers for reference in the first time, which became the most effective auxiliary tool for criminal investigation.

Figure 2: The criminal police department's intelligent "Criminal Knowledge Base".

\section{Results and Discussion-Coast Guard's Law and Regulations}

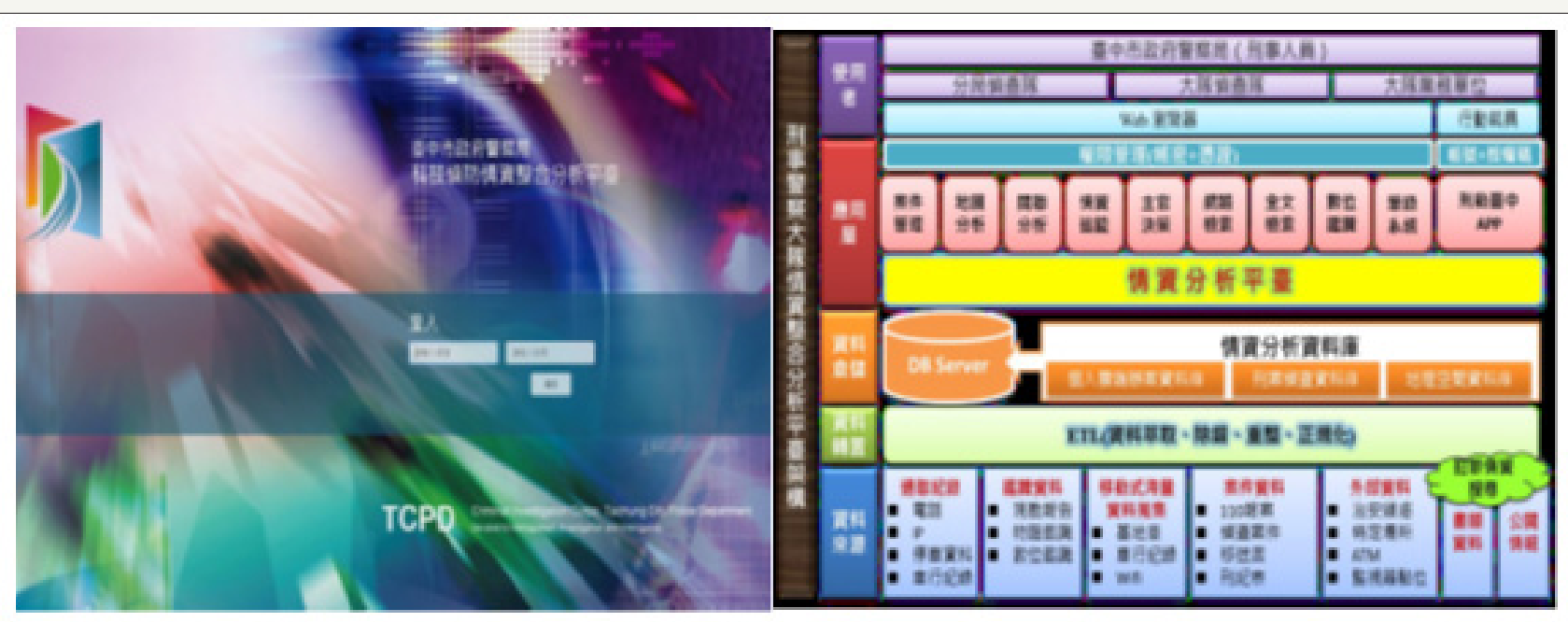

Figure 3: Taichung city police department information integration analysis platform. 


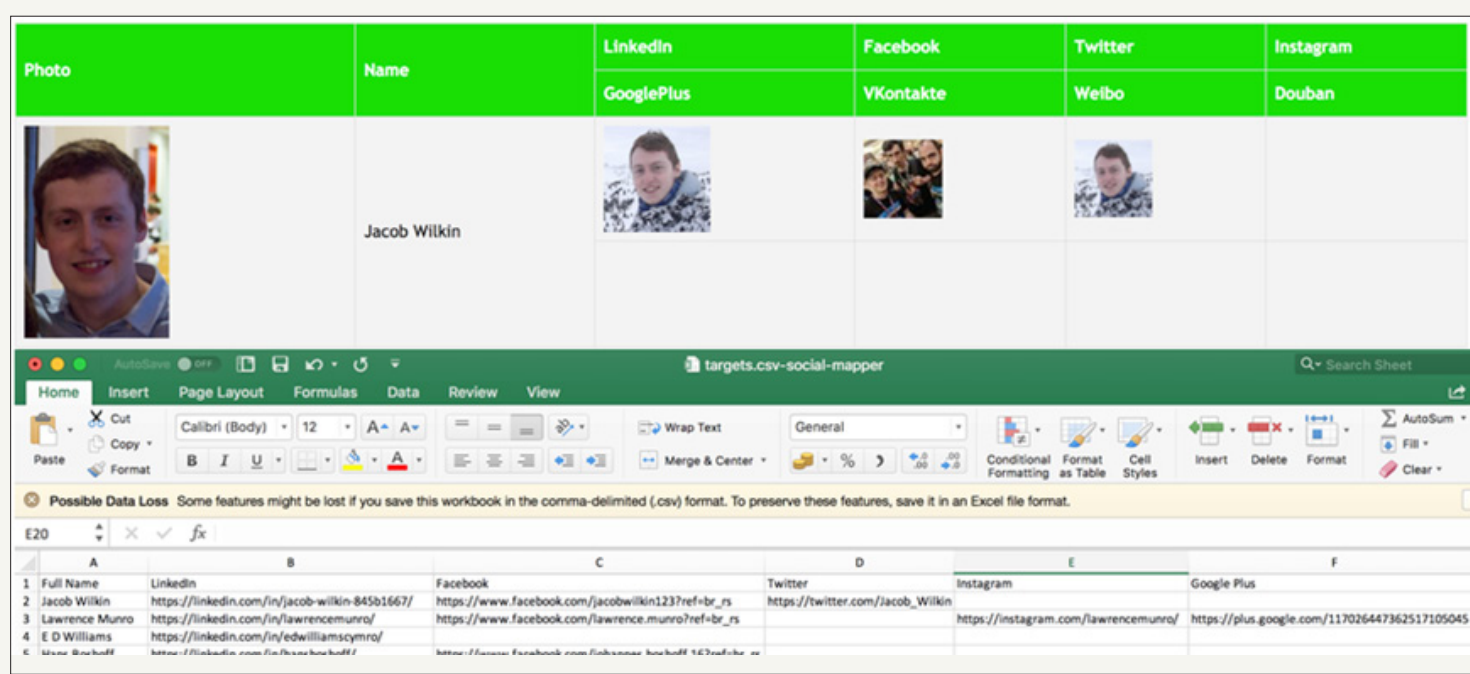

Figure 4: Social media by trustwave.

All kinds of sources of information will be built into a data warehouse, and various criminal investigation resources will be integrated to build a cloud case-handling platform to enhance the effectiveness of criminal investigation. The analysis uses the communication records, vehicle records, electronic maps, 110 reports, surveillance systems and other materials, supplemented by friendly use interface, providing the chief executive decisionmaking service planning, criminal investigation case management, auxiliary investigation, warning tracking and other four functions Figure 3. Trustwave develops the Social Mapper software, an intelligence gathering tool based on face recognition technology, can be used to search for personal files on social networking sites. The software supports 8 social networking platforms such as LinkedIn, Facebook, Twitter, Google+, Instagram and Weibo. Just enter the name. With the photos, you can automatically search for the personal files related to the target audience on the social networking platform and create a CSV file or a more visual HTML report that aggregates the target social networking links Figure 4.

\section{Conclusion and Future Study}

In the era of rapid development of information data, in order to grasp the trend of crime and effectively prevent crime, it has gradually developed the analysis of crime, criminal justice and case management through data science and data forensics. As far as criminal investigations are concerned, various data are collected through monitors, databases and other means for analysis to assist in investigations, focusing on the scope of investigation, reducing human resources, shortening investigation time, speeding up investigations, and improving the rate of crime detection, becoming the era of big data. the trend of. Make good use of big data analysis technology, master the core of crime problems, crime patterns and criminal pulsations, research and develop effective countermeasures, and provide timely sharing and application of various units to make crime prevention work more precise, more predictive and comprehensive, and improve the overall situation. Detection and prevention capabilities.

At present, the integration platform and digital identification of the Big Data Database of the Investigation and Prevention Department of the Coastal Defence Department of the Marine Commission is the initial stage of construction. For the future construction and functional development, we can refer to the requirements of the establishment of European and American advanced countries, materials and local conditions. Construct a criminal investigation and integration model that conforms to the characteristics of the unit. With the core concept of "technical case handling, emotional integration, and smart sea patrol", we will integrate case handling resources, collect accumulated data bases, and construct cloud services every year to create a better-quality sea patrol environment.

\section{References}

1. Xu Huafu, Wu Jiyu (2015) Big data development trends and applications in crime prevention, proceedings of criminal policy and crime research, Taiwan, p. 18.

2. Liu Bangqian, Weng Yi (2017) Big data applied to the study of crime analysis in the sea, exchange papers on cross-strait and Hong Kong and Macao police seminars, 12 sessions.

3. Hu Shizhong (2013) The killer application of the cloud era: Big data massive data analysis, Taipei, World Magazine, Taiwan, pp. 63-67.

4. Chen Xianqing, Zhu Meiping (2012) The metamorphosis of criminal investigation data exchange platform. Criminal Bimonthly 47: 10-15.

5. Coastal Patrol Agency.

6. Criminal Police Department.

7. Taiwan Smart City Industry Alliance. 
Creative Commons Attribution 4.0 International License

For possible submissions Click Here

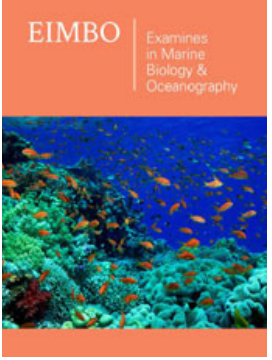

Examines in Marine Biology \& Oceanography

\section{Benefits of Publishing with us}

- High-level peer review and editorial services

- Freely accessible online immediately upon publication

- Authors retain the copyright to their work

- Licensing it under a Creative Commons license

- Visibility through different online platforms 